\title{
OPEN Heat tolerance and thermal preference of the copepod Tigriopus californicus are insensitive to ecologically relevant dissolved oxygen levels
}

\author{
Khuong V. Dinh ${ }^{1 凶}$, AraniY. Cuevas-Sanchez ${ }^{1}$, Katherine S. Buhl ${ }^{1}$, Elizabeth A. Moeser ${ }^{2}$ \& \\ W. Wesley Dowd ${ }^{1}$
}

Shifting climate patterns may impose novel combinations of abiotic conditions on animals, yet understanding of the present-day interactive effects of multiple stressors remains under-developed. We tested the oxygen and capacity limited thermal tolerance (OCLTT) hypothesis and quantified environmental preference of the copepod Tigriopus californicus, which inhabits rocky-shore splashpools where diel fluctuations of temperature and dissolved oxygen (DO) are substantial. Egg-mass bearing females were exposed to a $5 \mathrm{~h}$ heat ramp to peak temperatures of $34.1-38.0^{\circ} \mathrm{C}$ crossed with each of four oxygen levels: $22,30,100$ and $250 \%$ saturation (4.7-5.3, 5.3-6.4, 21.221.3 , and 50.7-53.3 kPa). Survival decreased at higher temperatures but was independent of DO. The behavioral preference of females was quantified in seven combinations of gradients of both temperature $\left(11-37^{\circ} \mathrm{C}\right.$ ) and oxygen saturation (17-206\% or 3.6-43.6 kPa). Females avoided high temperatures regardless of DO levels. This pattern was more pronounced when low DO coincided with high temperature. In uniform temperature treatments, the distribution shifted toward high DO levels, especially in uniform high temperature, confirming that Tigriopus can sense environmental $\mathrm{pO}_{2}$. These results question the ecological relevance of OCLTT for Tigriopus and raise the possibility of microhabitat selection being used within splashpool environments to avoid physiologically stressful combinations of conditions.

Marine organisms are facing increasing prevalence of multiple stressors, particularly extreme temperatures and heatwaves ${ }^{1-5}$ and low dissolved oxygen ${ }^{6-9}$. Furthermore, stressors can interact and modulate each other's effects $^{10-12}$. For example, extreme temperatures decrease the oxygen solubility while simultaneously increasing the organism's oxygen demand, hence intensifying hypoxic stress on marine species ${ }^{7,13}$. To locally survive, organisms may have to adjust their physiology $y^{14-16}$ and/or behaviors ${ }^{14,17,18}$ to cope with or avoid stressful conditions. However, we know relatively little about the prevalence and magnitude of the present-day interactions among stressors and their impacts on marine species ${ }^{10-12}$.

A prevailing theory suggests that thermal tolerance, particularly of aquatic water-breathers, is dependent upon oxygen availability. Specifically, this theory posits that thermal tolerance is determined by the capacity for oxygen supply in relation to oxygen demand; these ideas are encapsulated in the Oxygen and Capacity Limited Thermal Tolerance hypothesis (OCLTT) ${ }^{19-21}$. There are physiological studies supporting OCLTT, particularly during acute thermal stress events. For example, the critical thermal maxima $\left(\mathrm{CT}_{\max }\right)$ of fish increases under hyperoxia ${ }^{22}$. Yet, there is increasing evidence questioning the generality and ecological relevance of the OCLTT hypothesis ${ }^{23-26}$. For example, Lehmann et al. ${ }^{27}$ found that $\mathrm{CT}_{\max }$ of the pupae of the butterfly Pieris napi was $43.1 \pm 0.5^{\circ} \mathrm{C}$, and it did not change across the range of ambient $\mathrm{O}_{2}$ from 10 to $30 \mathrm{kPa}$. Similarly, the heat tolerance of grasshopper larvae (Schistocerca americana) was not decreased under hypoxic conditions ${ }^{25}$. These counter-examples often come from terrestrial systems, but recent work also questions the predictions of OCLTT in water-breathers such as fish ${ }^{4}$.

${ }^{1}$ School of Biological Sciences, Washington State University, P.O. Box 644236, Pullman, WA 99164-4236, USA. ${ }^{2}$ Department of Environmental Studies, University of Southern California, Los Angeles, CA, USA. ${ }^{\square}$ email: khuong.dinh@wsu.edu 


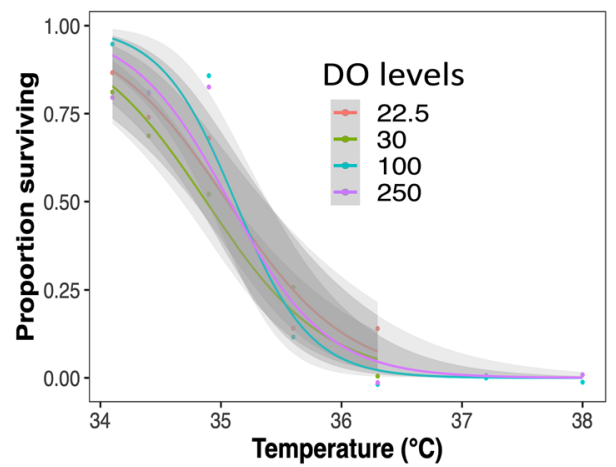

Figure 1. The survival of Tigriopus californicus females at different dissolved oxygen levels. Grey shaded areas indicate overlapping $95 \%$ confidence intervals.

By similar logic, it is also possible that oxygen levels influence organismal temperature preferences. Mobile species can employ behavioral adjustments to avoid stressful conditions by selecting specific microhabitats in spatially heterogeneous environments ${ }^{14,18}$. Indeed, spatial heterogeneity is a widespread feature of natural habitats ${ }^{28,29}$, even in small splashpools ${ }^{29,30}$. Behavioral adjustments can provide an alternative mechanism to rescue species from stressful conditions ${ }^{14,17,18}$. Many species can adjust their position to seek preferred thermal and oxygen zones ${ }^{31,32}$. For example, the American lobster (Homarus americanus) responded to changes in water temperature by leaving their shelter and seeking temperatures within $\sim 1.2^{\circ} \mathrm{C}$ of the acclimation temperature $\mathrm{r}^{31}$. Similarly, Cyclops vicinus copepods showed their highest distribution (presence) within their optimal thermal conditions $^{33}$. Calanoid copepod species prefer oxygen-rich water while cyclopoid Oihona similis and Oncaea sp. often aggregate in high abundance in the midwater hypoxic zone ${ }^{32}$. Fewer studies have examined preference behaviors in a multi-stressor context, and those showed that fish have a lower temperature preference in hypoxic conditions than in normoxia ${ }^{34,35}$. Overlooking the potentials of behavioral responses to multiple stressors such as extreme temperatures and low dissolved oxygen (DO) levels may fail to accurately quantify the real risk of environmental changes in natural populations ${ }^{17,18}$.

Harpacticoid copepods in the genus Tigriopus are excellent species to study physiological and behavioral responses to single and covaring stressors. These species are commonly found in splashpools ${ }^{36-38}$, where the diel fluctuations of temperatures and DO are substantial ${ }^{30}$. High temperatures $\left(>30^{\circ} \mathrm{C}\right)$ tend to coincide with high DO levels (>200\% saturation) during the day due to the elevated solar radiation and photosynthesis; low temperatures and low DO conditions are observed during the night ${ }^{30}$. Tigriopus spp. show a high tolerance to temperatures ${ }^{39-41}$ and low $\mathrm{DO}^{42-44}$ independently. However, the majority of these studies have investigated the impact of one stressor at a time, thereby leaving unexplored the potential for interactive effects that might impact organisms experiencing multiple stressors simultaneously in nature ${ }^{15}$. The behavioral responses of Tigriopus to temperature, dissolved oxygen, and their combination remain to be tested.

In this study, we combined physiological and behavioral tests to comprehensively assess whether (1) ecologically relevant high (low) oxygen levels may increase (decrease) heat tolerance of Tigriopus californicus, as predicted by the OCLTT hypothesis, and (2) copepods modulate their thermal preference depending on oxygen levels.

\section{Results}

Thermal tolerance. As expected, there was a significant main effect of temperature on survival of T. californicus $\left(\chi_{1}^{2}=51.20, P<0.001\right)$. Specifically, survival decreased rapidly with increasing temperatures, from an average of approximately $90 \%$ at $34.1-34.9{ }^{\circ} \mathrm{C}$ to $<10 \%$ at $36.3{ }^{\circ} \mathrm{C}$. No females survived at 37.2 and $38.0{ }^{\circ} \mathrm{C}$ (Fig. 1). Survival did not differ among low, normal and high DO levels $\left(\chi_{1}^{2}=0.72, P=0.40\right)$. The interaction of temperature and DO also was not statistically significant $\left(\chi_{1}^{2}=0.69, P=0.41\right)$. Thus, the temperature-induced mortality of T. californicus was independent of oxygen at the levels tested.

Thermal and oxygen preferences. Overall, females avoided high temperatures regardless of the oxygen levels in the water (Fig. 2A-D). The distribution of females tended to shift more toward lower temperatures when the oxygen levels were high in this part of the chamber (Fig. 2B,C, pairwise comparisons between treatments 2 , 3 and treatment $1, P=0.075$ and 0.051 , respectively); this pattern was less clear when low DO occurred across the thermal gradient (Fig. 2D, pairwise comparisons of treatment 4 and treatments $1-3$, all $P$-values $<0.05$ ). Female distributions were skewed toward high oxygen levels when there was no thermal gradient (Fig. 2E,F, pairwise comparisons between treatments 5 or 6 and $1-4$, all $P$-values $<0.001$ ), and this pattern was stronger at $36^{\circ} \mathrm{C}($ Fig. $2 \mathrm{~F})$ than at $12{ }^{\circ} \mathrm{C}$ (Fig. $2 \mathrm{E}$, pairwise comparison between treatment 5 and treatment $6, P<0.001$ ). When there were no temperature and oxygen gradients, females were distributed evenly in the chambers, and no preferred positions were observed (Fig. 2G, pairwise comparisons between treatment 7 and treatments 1-6, all $P$-values $<0.001)$. A full list of pairwise $P$ values is provided in Table $S 1$ in Supplementary information S2. 

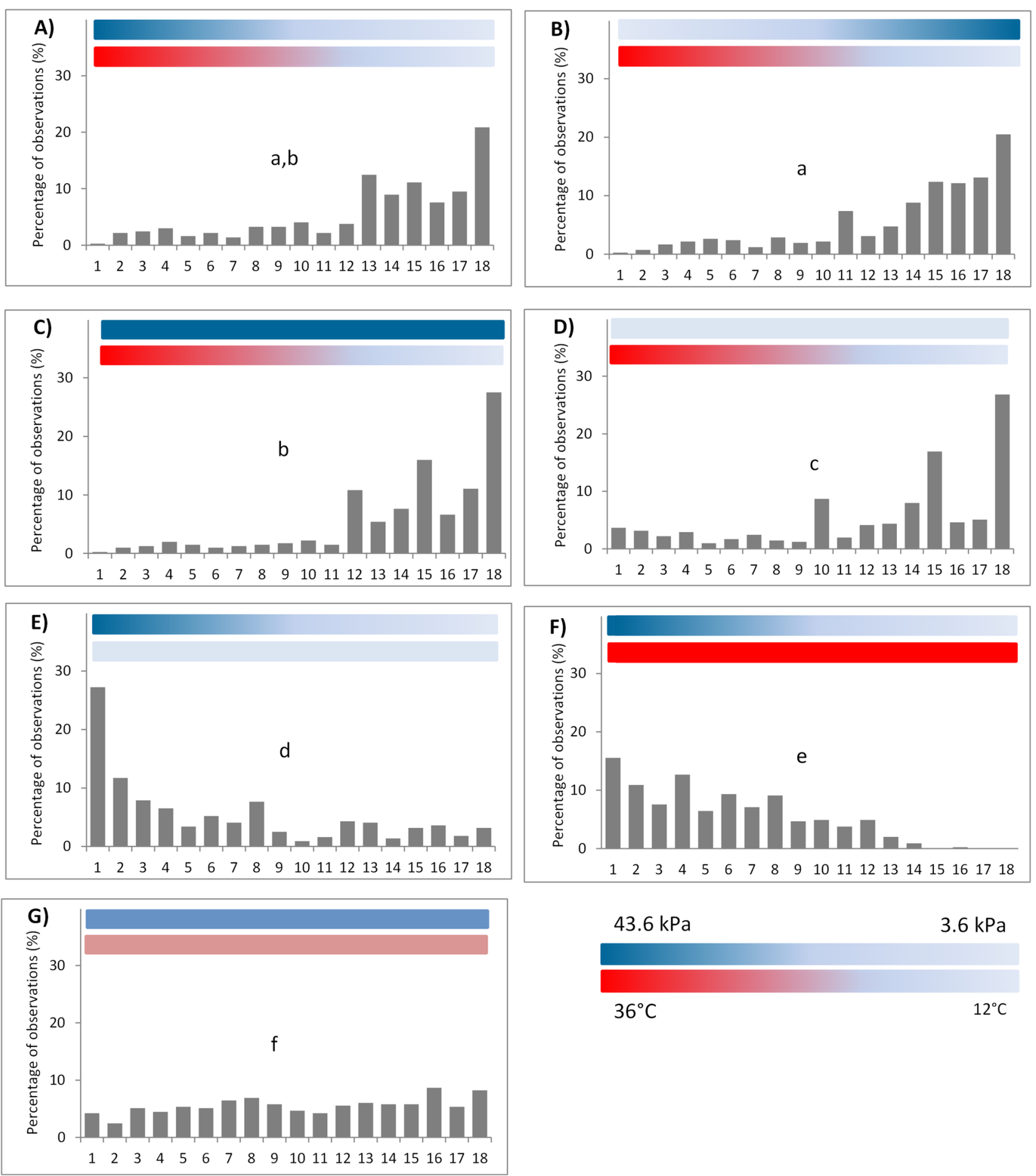

$43.6 \mathrm{kPa}$

$3.6 \mathrm{kPa}$

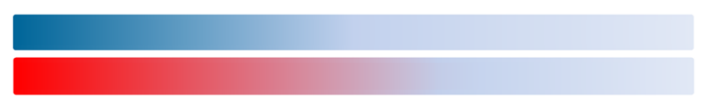

$36^{\circ} \mathrm{C}$

$12^{\circ} \mathrm{C}$

Figure 2. The distribution of Tigriopus californicus females in response to gradients of temperature, oxygen, or both within assay chambers. Data are the cumulative percentages (\%) of observations in which females were observed in each of the positions from 1 to 18 in the test chambers. The colored horizontal bars within each panel illustrate the ranges of temperature and dissolved oxygen presented in each treatment. Statistical differences $(P<0.05)$ among treatment groups are indicated by different lowercase letters. Panels A-G represent Treatments $1-7$, respectively.

Distance traveled. Copepods were considerably more active in the uniform (no gradients) treatment of intermediate temperature and normal DO conditions relative to all other treatments. For every minute, they traveled $4.8 \mathrm{~cm}$, ca. 2-3 times greater than the average distance traveled by copepods in all other treatments (Kruskal-Wallis, $\mathrm{H}_{6,101}=23.30, P<0.001$, Fig. 3). There was no difference in distance traveled by copepods among the other treatments (all pairwise $P$ values $>0.10$, Table S2 in Supplementary information S2). 


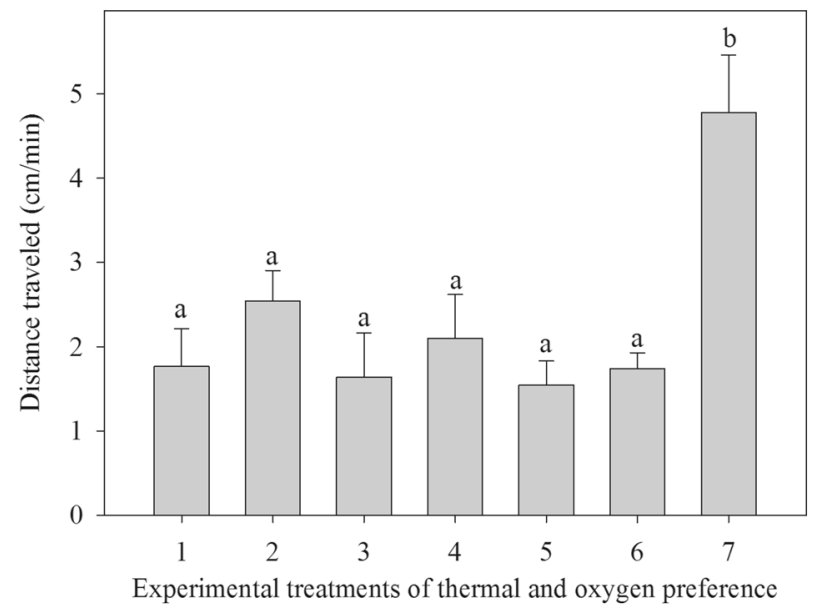

Figure 3. The average distance $(\mathrm{cm})$ traveled per minute by Tigriopus californicus females in response to the thermal and oxygen gradients in the test chambers. Data are means +1 SE. Statistical differences $(P<0.05)$ among treatments are indicated by lowercase letters above the bars.

\begin{tabular}{|c|c|c|c|c|c|}
\hline \multirow[b]{2}{*}{ Treatments } & \multicolumn{2}{|l|}{ Header tank 1} & \multicolumn{2}{|l|}{ Header tank 2} & \multirow[b]{2}{*}{ Gradients } \\
\hline & Temperature $\left({ }^{\circ} \mathrm{C}\right)$ & Dissolved oxygen (\% saturation) & Temperature $\left({ }^{\circ} \mathrm{C}\right)$ & Dissolved oxygen (\% saturation) & \\
\hline $\mathrm{T} 1$ & $36.7 \pm 0.1$ & $198.1 \pm 1.9$ & $11.8 \pm 0.6$ & $21.0 \pm 4.3$ & Parallel temperature and DO gradients \\
\hline $\mathrm{T} 2$ & $36.6 \pm 0.2$ & $26.4 \pm 2.9$ & $12.0 \pm 0.3$ & $193.7 \pm 1.7$ & Inverse temperature and DO gradients \\
\hline $\mathrm{T} 3$ & $36.5 \pm 0.2$ & $199.0 \pm 2.3$ & $11.7 \pm 0.6$ & $198.4 \pm 1.9$ & $\begin{array}{l}\text { Temperature gradient. No DO-gradient (high } \\
\text { DO) }\end{array}$ \\
\hline $\mathrm{T} 4$ & $36.7 \pm 0.1$ & $26.9 \pm 0.4$ & $11.3 \pm 0.5$ & $31.2 \pm 2.6$ & $\begin{array}{l}\text { Temperature gradient. No DO-gradient (low } \\
\text { DO) }\end{array}$ \\
\hline T5 & $12.2 \pm 0.4$ & $198.1 \pm 0.4$ & $11.7 \pm 0.1$ & $27.9 \pm 8.2$ & $\begin{array}{l}\text { No temperature gradient (cool temperature). } \\
\text { DO-gradient }\end{array}$ \\
\hline T6 & $36.5 \pm 0.1$ & $197.0 \pm 9.5$ & $36.3 \pm 0.1$ & $31.5 \pm 1.2$ & $\begin{array}{l}\text { No temperature gradient (warm temperature). } \\
\text { DO-gradient }\end{array}$ \\
\hline T7 & $19.6 \pm 0.2$ & $100.1 \pm 1.3$ & $19.4 \pm 0.3$ & $98.4 \pm 2.6$ & $\begin{array}{l}\text { No temperature gradient (intermediate tem- } \\
\text { perature). No DO gradient, normoxic. (control } \\
\text { treatment) }\end{array}$ \\
\hline
\end{tabular}

Table 1. The measured temperatures and dissolved oxygen in the experimental system for the preference behavior test. Data are means \pm SD.

\section{Discussion}

There is extensive evidence that the splashpool copepods of the genus Tigriopus can tolerate extremely highamplitude fluctuations of environmental conditions $s^{36,37,45,46}$. Our results showed strong mortality at temperatures higher than $34.9^{\circ} \mathrm{C}$ and only less than $10 \%$ of females survived after being exposed to $36.3^{\circ} \mathrm{C}$; no surviving females were observed after exposure to 37.2 and $38.0^{\circ} \mathrm{C}$. These results are comparable to published estimates of the thermal tolerance of $T$. californicus from the same climatic zone ${ }^{37,38,47}$. The thermal tolerance of T. californicus populations have been physiologically linked to the ATP synthesis capacity in the mitochondria; ATP synthesis declines at temperatures close to the knockdown temperatures ${ }^{38}$. The level of heat shock protein upregulation also has a positive correlation to thermal tolerance of T. californicus $^{41}$. Suppression of a specific heat shock protein (HSPB1) has been shown to reduce the thermal tolerance of T. californicus to acute heat stress ${ }^{17,48}$.

Importantly, the overall survival of T. californicus did not decrease at two low, but ecologically relevant DO conditions relative to normal DO ( 100\% saturation), regardless of peak exposure temperatures, nor did high DO level mitigate the effects of acute thermal stress. These results appear to contradict predictions of OCLTT ${ }^{19,21}$. A role for OCLTT, particularly during acute heat stress such as imposed in our experiments, is supported by evidence from a range of taxa in both aquatic and terrestrial ecosystems (reviewed in Table 1 in Ref. ${ }^{21}$ ). However, it is likely that insensitivity of thermal tolerance to low DO levels occurs in species with high capacity to regulate oxygen intake and delivery (e.g., in the snail Planorbis planorbis) or when DO levels are not lower than the critical levels (e.g., $\mathrm{P}_{\text {crit }}$ of 1.1-1.3 kPa for T. californicus ${ }^{50}$ ). For example, the snail Planorbis planorbis has 2-4 times higher hemoglobin levels than its congeners ${ }^{51}$; under hypoxic conditions the thermal tolerance of $P$. planorbis was not reduced, but the CTmax of $P$. carinatus was lowered by $1.2-2.1^{\circ} \mathrm{C}^{49}$. Tigriopus species do not have gills, lack respiratory pigments ${ }^{50}$, and appear to have lost both the transcription factor HIF-1 $\alpha$ and oxygen sensing prolyl hydroxylase repressor, EGLN, from their genome ${ }^{43}$. It has been suggested that a high surface-area-to-volume 
ratio of Tigriopus spp. may facilitate oxygen uptake from water ${ }^{50}$. This may allow them to maintain their oxygen consumption rate independent of $\mathrm{P}_{\mathrm{O} 2}$ in the environment until the critical $\mathrm{P}_{\mathrm{O} 2}$ of $1.1-1.3 \mathrm{kPa}^{50}$, which is approximately 4-5 times lower than the lowest $\mathrm{P}_{\mathrm{O} 2}$ of ca. 4.7-5.3 kPa in our experiment. Therefore, the insensitivity of thermal tolerance of $T$. californicus to low, but ecologically relevant DO levels observed in our experiment was in line with previous studies; reduced thermal tolerance of water-breathing species has been observed only at extremely low DO levels ${ }^{4,26}$. As noted above, in the splashpool system, DO levels below $\mathrm{P}_{\text {crit }}$ of T. californicus are exceedingly unlikely to coincide with high temperatures.

Therefore, the oxygen level may not be the limiting factor for thermal tolerance in ecologically relevant scenarios for Tigriopus and in similar cases. Instead, the capacity to physiologically cope with other consequences of temperature extremes may be the primary determinant of their thermal tolerance. Mortality under extreme temperatures may be the result of the dysfunction of a number of physiological processes such as the collapse of ATP synthesis ${ }^{38}$, membrane and protein structure instability ${ }^{52,53}$, and suppressed expression of heat shock protein (HSPB1 $)^{17,48}$. In light of our whole-organism survival data, we hypothesize that macromolecular disruption, rather than any direct effect of oxygen availability, explains recently published patterns of decreased ATP production capacity in Tigriopus mitochondria ${ }^{38}$, particularly because those in vitro experiments appear to have been run under normoxic conditions.

Irrespective of the mechanism(s) for the insensitivity of the thermal tolerance of T. californicus to ecologically relevant DO levels, our results join a growing literature suggesting that the OCLTT hypothesis may not be a universal principle for predicting the survivability of species in ecologically relevant conditions in nature ${ }^{4,26}$. Whether the exceptional environmental covariation of temperatures and DO levels in splashpools has selected for high thermal tolerance regardless of DO levels remains to be seen; it is equally plausible that selection for surviving periods of extreme night-time low DO may have coincidentally increased the ability to survive bouts of high temperature using anaerobic ATP production pathways. Recent work reveals that T. californicus can survive several days of anoxia ${ }^{43}$. It also is clear that the elevated DO levels that tend to naturally coincide with high temperatures in splashpools ${ }^{30}$ do little to alleviate the effects of high temperature stress on these animals. Although beyond the focus of this study, it will be interesting to explore whether low DO levels may also alter critical thermal minimum $\left(C T_{\min }\right)$ of $T$. californicus and other species when low DO levels in their habitats occur during cold nights or the winter period ${ }^{54}$. In terrestrial ecosystems, the $C T_{\min }$ values of some insects such as false codling moth Thaumatotibia leucotreta ${ }^{55}$, the beetle Tenebrio molitor ${ }^{56}$ and crustaceans such as Porcellio scaber $^{56}$ are independent of oxygen availability.

Overall, female T. californicus demonstrate a strong avoidance of elevated temperatures, with oxygen playing a secondary role in influencing behavior. For example, their high distribution in the low DO region in treatment 1 (Fig. 2A) was likely just to avoid the potentially lethal effects of extreme temperatures in the oxygen-rich water. The distribution of T. californicus was considerably more concentrated in oxygen-rich water only when low temperatures coincided with high oxygen (Fig. 2B,C) or there was no thermal gradient in the chambers (Fig. 2E,F). These results suggest that T. californicus can avoid low DO conditions.

Interestingly, the genome of T. californicus appears to lack prolyl hydroxylase and HIF- $1 \alpha^{43}$, but our results clearly illustrate that these animals can sense the relative abundance of oxygen in the water. These results imply the existance of an alternative, extracellular (and perhaps superficial) mechanism(s) for T. californicus to sense $\mathrm{pO}_{2}$. Under uniformly extreme high temperatures, a shift in the distribution of females toward oxygen-rich water was even stronger; none were found in the low DO regions (Fig. 2F). This may be the result of higher basal metabolic demand, indicated by a general higher oxygen consumption rate at higher temperatures in a congener ${ }^{50}$. Finally, T. californicus did not show any preferred region within the chambers when they were in the control treatment at room temperature of $19^{\circ} \mathrm{C}$ and the DO was maintained at $100 \%$ saturation. They also traveled a longer distance in this control treatment than in all other treatments, an indication that our observations of their distributions were consistent throughout the trial and uninfluenced by other confounding factors such as light.

Lastly, the behavioral results complement the physiological results to suggest a potentially novel explanation for how T. californicus can thrive in splashpools, where both temperature and DO are highly fluctuating and often extreme. Specifically, the results for thermal tolerance suggest that $T$. californicus may occasionally not be able to physiologically cope with extreme temperature. To survive in splashpools with extremely high temperatures during the day, there must be an alternative mechanism. Interestingly, field observations indicate that splashpools may be highly stratified over their small spatial scales of a few $10 \mathrm{~s}$ of centimeters or less (Fig. S1 in Supplementary information S1, Ref. ${ }^{30}$ ). Indeed, our behavioral preference test showed that females avoided near-lethal temperatures even if by doing so they had to deal with lower oxygen levels at lower temperatures. This behavioral preference of $T$. californicus, which remains to be demonstrated in a natural setting, supports a recent prediction that behavioral responses of natural populations may enable them to exploit microclimatic variations in heterogeneous habitats as an important mechanism to rescue species from rapidly changing environments ${ }^{17,18}$.

Our study provides empirical evidence for the insensitivity of both heat tolerance and thermal preference of the splashpool copepod T. californicus to the ambient DO level. These patterns apply in ecologically relevant low and high DO conditions. It is likely that warming may be more stressful for T. californicus than low DO levels. Our results are among a small but growing collection of studies showing that the OCLTT hypothesis may not be a universal tool for predicting the thermal tolerance of species, particularly in ecologically relevant scenarios where environmental conditions fluctuate dynamically across a small scale of space and time. The strong behavioral preference of $T$. californicus suggests that together with physiological adjustments ${ }^{39-41}$, microhabitat selection might be used as an alternative mechanism for T. californicus to survive in highly fluctuating and often extreme conditions in splashpools ${ }^{30}$. 


\section{Materials and methods}

Study population. Female Tigriopus californius were collected in May 2019 from splashpools at Cattle Point Lighthouse $\left(+48^{\circ} 27^{\prime} 1.44^{\prime \prime} \mathrm{N},-122^{\circ} 57^{\prime} 48.6^{\prime \prime} \mathrm{W}\right)$ on San Juan Island, WA, USA. The copepods were acclimated to the laboratory condition at $17-18^{\circ} \mathrm{C}$ for 2 to 4 months (at least $1-2$ laboratory-reared generations). Copepods were fed ad libitum on fish flakes and an irradiated algae mixture (Shellfish Diet 1800, Reed Mariculture), each provided once a week. They were kept under a photoperiod of 13L:11D (light:dark cycle). Salinity values correspond to the practical scale of 32.5-42.0 and dissolved oxygen (DO) was maintained above $80 \%$ of the saturation level $\left(>6 \mathrm{mg} \mathrm{L}^{-1}\right)$ throughout the acclimation period. Salinity and DO were measured using a YSI digital meter (Pro 2030, Yellow Springs Instruments, USA).

Thermal tolerance assay at different dissolved oxygen levels. The thermal tolerance of $T$. californicus was quantified based on survival after exposing females to peak temperatures of 34.1, 34.4, 34.9, 35.6, 36.3, 37.2 and $38.0^{\circ} \mathrm{C}$ at different DO levels. Specifically, females carrying egg masses ( 380 individuals, $\mathrm{n}=15-16$ per temperature $\times \mathrm{DO}$ combination) were randomly collected from the culture and exposed to a $5 \mathrm{~h}$ heat ramp at one of the peak temperatures $\left(34.1-38.0^{\circ} \mathrm{C}\right.$ ) at each of four DO levels: $22.5,30,100$ and $250 \%$ of the oxygen saturation level. Both DO and peak temperatures are ecologically relevant to the splashpools at the collection site. Individual females were placed in $0.2 \mathrm{~mL}$ PCR tubes (conical shape, $\mathrm{h}=20.8 \mathrm{~mm}$ and $\mathrm{d}_{\text {top }}=5.46, \mathrm{~d}_{\text {bottom }}=2.8 \mathrm{~mm}$ ) filled with $150 \mu \mathrm{L}$ of the appropriate seawater (32 ppt) and DO level. Copepods could swim freely inside the tubes during the test, and they exhibited typical swimming behavior after the test.

To create different DO levels in the PCR tubes during the heat ramp, we prefilled tubes with seawater adjusted to one of the desired levels. Dissolved oxygen levels were manipulated in a $20 \mathrm{~L}$ water bath using a custom-built, Arduino microcontroller system that regulated DO (while maintaining a constant $\mathrm{pH}$ of $\sim 8.05$ ) by coordinating the opening/closing of solenoid valves connected to oxygen, carbon dioxide, and nitrogen gas cylinders. The systems included calibrated temperature, DO (Honeywell DL5000), and pH (Honeywell Durafet III) sensors connected to a Honeywell UDA1282 Universal Dual Analyzer. The milliamp outputs of this analyzer provided feedback to the Arduino on the current conditions in a header tank; after comparing the current conditions to the desired setpoints, the Arduino triggered brief (10 s of milliseconds) pulsed openings of the solenoid valves to regulate gas flow. This cycle continued on a continuous loop, constantly monitoring and maintaining the DO level. Target DO levels (in mm Hg) were confirmed in the PCR tubes using a fiberoptic oxygen sensor (Neofox, Ocean Optics) prior to the tubes being capped and sealed with parafilm. To sustain these DO levels during the heat ramp, the entire thermocycler used for the thermal tolerance assay was housed in a sealed incubator, in which we manipulated the atmospheric oxygen levels in parallel with the desired DO in the seawater by pumping nitrogen or oxygen into the incubator. This arrangement was necessary because in preliminary trials all DO levels equilibrated with the atmosphere by the mid-way point of the 5-h heat ramp. Due to safety concerns around high-amperage electrical equipment, we could only increase oxygen levels in the incubator to $150 \%$ saturation. Using the incubator, DO levels within the PCR tubes were 4.7-5.3, 5.3-6.4, 21.2-21.3, and 50.7-53.3 kPa (22, 30, 100 and $250 \%$ saturation), respectively, at the start of the thermal tolerance assay. We confirmed in preliminary trials that these target DO levels in PCR tubes (each containing one female copepod) were maintained during the heating phase until reaching the peak temperature, but they drifted by the end of the assay. At the completion of the heat ramp, DO levels in the PCR tubes were 12.7-13.3, 14.0-14.4, 21.2-21.3, and 40-42.7 kPa (60-62, $66-67.5,100,188-200 \%$ saturation, respectively). Thus, although DO conditions did not remain constant for the entire duration of the heat ramp, they remained different from each other. Both low DO treatments (22.5 and $30 \%$ saturation) remained within the ecologically relevant low DO ranges found in splashpools during the heating phase ${ }^{30}$. Experimental assays were run using identical methods as these preliminary trials, but we did not measure DO levels in PCR tubes for experimental copepods.

For each heat ramp, PCR tubes were placed in an Eppendorf Mastercycer gradient thermocycler, which was custom-programmed to generate a gradual rise and fall of temperature over a five-hour period. The start temperature for the heat ramp was $20^{\circ} \mathrm{C}$. The thermocyler was programmed to a new setpoint every $10 \mathrm{~min}$. Over the first $25 \mathrm{~min}$ all columns increased by $1{ }^{\circ} \mathrm{C}$. Subsequent setpoints were programmed to increase $1{ }^{\circ} \mathrm{C}$ every $10 \mathrm{~min}$ to a preset peak temperature of $37 \pm 3{ }^{\circ} \mathrm{C}$ at $185 \mathrm{~min}$. Using the gradient feature, each column reached a unique peak temperature of $34.1,34.4,34.9,35.6,36.3,37.2$ or $38.0^{\circ} \mathrm{C}$. Upon reaching the peak, the temperature was maintained for $1 \mathrm{~h}$. Following the 1 -h exposure, temperature was decreased to $20^{\circ} \mathrm{C}$ over the course of one hour. This protocol created a thermal profile more similar to the environmental temperature variation experienced by T. californicus in the wild ${ }^{39}$. Preliminary trials revealed that females exposed to low DO conditions and a peak temperature of $36^{\circ} \mathrm{C}$ suffered $100 \%$ mortality. In order to reduce unnecessary use of animals, it was determined that low DO levels, 22.5 and $30 \%$ saturation, combined with peak temperatures of 37.2 and $38.0^{\circ} \mathrm{C}$ would not be tested as part of this experiment. Therefore, a total of 40 females were tested at each of the low DO levels of $22 \%$ and $30 \%$, and 56 females were tested at the normal and high levels. This heat-ramp procedure was repeated twice at each dissolved oxygen level. DO levels were randomized and only one was examined per day. The survival of females was checked immediately after the ramp and daily for the following 4 consecutive days. Mortality was determined when females were unresponsive to mild shaking of the vial, changed colors to bright red, and the urosome was bent sharply at a right angle to the cephalothorax ${ }^{57}$. Statistical analyses were conducted using survival at day 4 .

Behavioral preference assay in the presence of temperature and oxygen gradients. To test whether DO may impact thermal preference of T. californicus, we determined the positions and distance traveled by egg-mass bearing females $(n=14-15$ individuals per treatment) in each of 7 treatment conditions (Table 1) in preference chambers (Fig. 4). Preference chambers were in-house designed based on the system for Daph- 


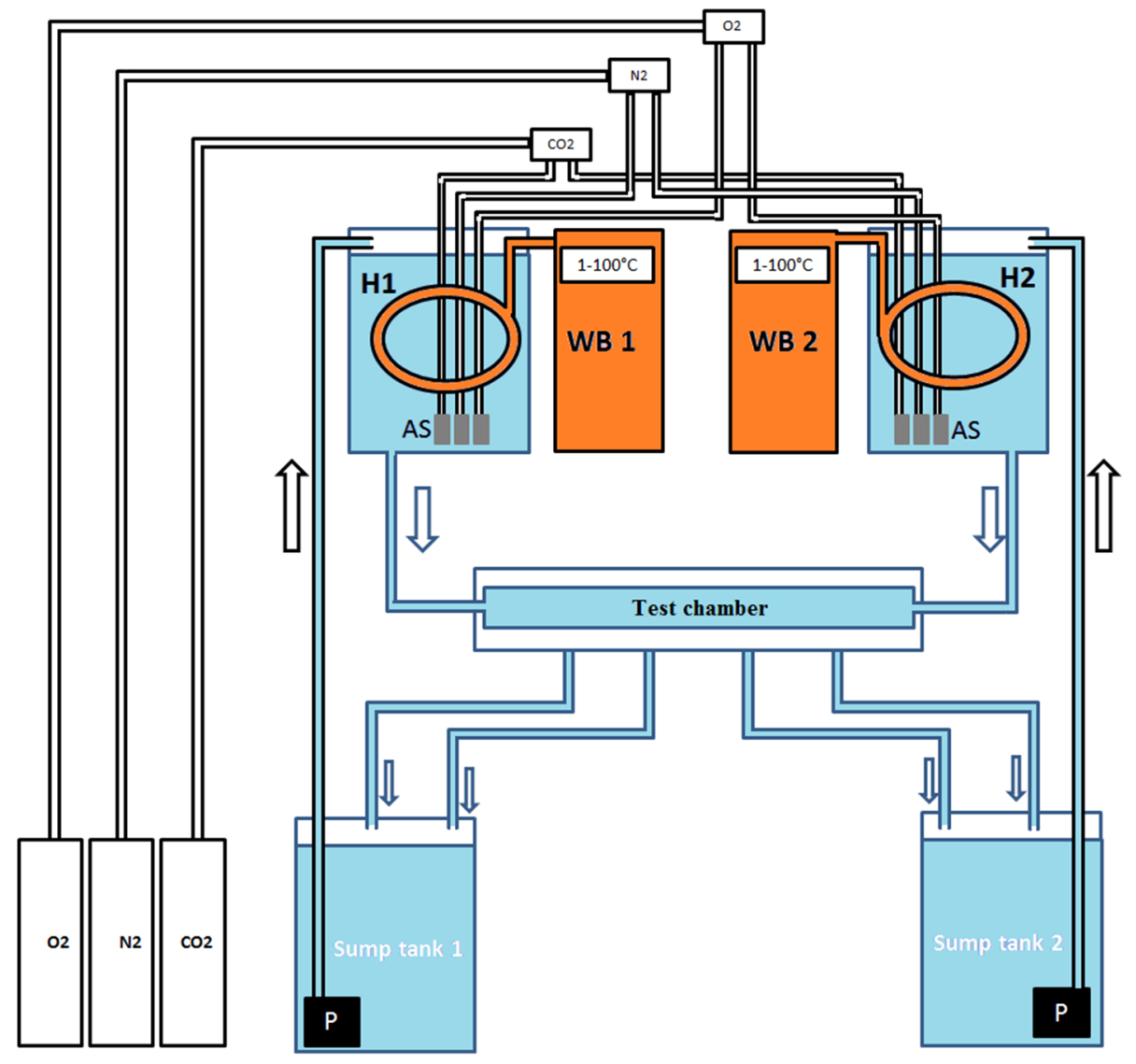

Figure 4. Experimental system for the behavioral preference assay, in the presence of oxygen and/or temperature gradients. $\mathrm{H} 1$ and $\mathrm{H} 2$ are header tanks where both temperatures and dissolved oxygen can be independently controlled within the ranges of $1-100^{\circ} \mathrm{C}$ and $0-200 \%$ saturation, respectively. WB1 and WB2 are water baths where temperatures were set up to control temperatures in the $\mathrm{H} 1$ and $\mathrm{H} 2$ tanks, respectively. Gases $\left(\mathrm{O}_{2}, \mathrm{~N}_{2}\right.$, and $\left.\mathrm{CO}_{2}\right)$ were fed from cylinders to each header tank via airstones, and an Arduino-controlled system pulsed gas flows independently to each header tank through solenoid valves to maintain $\mathrm{pH}$ and $p \mathrm{O}_{2}$ at desired levels. $\mathrm{AS}=$ Airstones and $\mathrm{P}=$ pump. Arrows indicate the directions of water flow.

nia magna described in Zeis et al. ${ }^{58}$, with extensive modifications (Fig. 4). Specifically, 5 identical chambers were constructed of acrylic $(\mathrm{L} \times \mathrm{W} \times \mathrm{H}=22.86 \times 1.27 \times 1.27 \mathrm{~cm}$, volume $=36.87 \mathrm{ml})$. The chamber was sealed with a rubber gasket and acrylic lid. It was divided into 18 equal intervals, $1.27 \mathrm{~cm}$ each, by marking the outside of the chamber. Copepods could swim freely throughout the chamber without any physical barriers. There were inlets at each end, which connect to two different header tanks (size: $\mathrm{L} \times \mathrm{W} \times \mathrm{H}=28.58 \times 31.12 \times 40 \mathrm{~cm}$; volume $=20.8 \mathrm{~L}$ ) where the water temperature and $\mathrm{DO}$ were controlled by two programmable, recirculating water baths and the $\mathrm{N}_{2}$ and $\mathrm{O}_{2}$ gas systems. The $\mathrm{pH}$ in the water was controlled at around $8.05 \pm 0.05$ by the $\mathrm{CO}_{2}$ gas system. Gas flows were automatically controlled by an in-house Arduino microcontroller system as described for the thermal tolerance assays above. Each preference chamber has 4 outlet ports distributed equally along one side (the distance between two adjacent outlet ports is $4.57 \mathrm{~cm}$ ); inlet and outlet ports were fitted with a $50 \mu \mathrm{m}$ mesh screen to prevent copepods swimming out of the chamber. The outflow rates were $0.8-0.9 \mathrm{~mL} / \mathrm{min}$ for outlets. This resulted in a total of roughly $3.25 \mathrm{~mL}$ water outflow per min, approximately $9 \%$ of the volume of the preference chamber. This flow rate is comparable to an assay for Daphnia magna ${ }^{58}$. Copepods swam freely throughout the preference chambers, therefore the flow did not impede the swimming or behavioral preferences of T. californicus. Two outlet ports from each side of the chamber were connected to one sump tank and two others were connected to a second sump tank. The sump tanks have the same size and volume as the two header tanks. The water in each of the sump tanks was pumped up to the corresponding header tank to create two closed and recirculating water systems, which could be regulated independently for temperature and DO.

Prior to an experiment, the desired temperature $\left(11\right.$ to $\left.37^{\circ} \mathrm{C}\right)$ and DO levels $(0-200 \%$ saturation) were established in the two header tanks using recirculating water baths and the Arduino system, respectively (see Table 1). In the chambers, we confirmed the temperature and DO gradients at 6 positions; temperature fluctuated $34.5-35.1^{\circ} \mathrm{C}$ at the high end; $28.3-30.6,25.5-27.1,18.5-22.7,15.7-18.4^{\circ} \mathrm{C}$ at the four outlet ports; and $13-13.4^{\circ} \mathrm{C}$ at the low end. Similarly, observed DO ranges from the high to low DO ends of the apparatus were $51.7-62.5,26.4-53.3,21.9-26.4,9.2-14.7,4.8-8.0$ and $0.7-3.2 \mathrm{kPa}$, respectively. These are also ecologically relevant for the temperature and DO levels observed in splashpools occupied by Tigriopus (Fig. S1-Supplementary 
information S1, Ref. ${ }^{30}$ ). For each experimental run, we randomly collected five egg-mass carrying females from the lab culture (temperature of $17-18^{\circ} \mathrm{C}$ ) and assigned one individual per preference chamber. In preliminary trials, we observed that copepods tended to modify their behavior in the presence of a con-specific, so our protocol isolated the effects of environment from any social factors.

Females were allowed $10 \mathrm{~min}$ to explore the chambers before beginning data collection. Our preliminary observations showed that females swam freely within the first three to five minutes, and subsequently showed a more stable position in the chamber. The female positions in each chamber were observed once per min for $29 \mathrm{~min}$ (30 observations). All preference assays were conducted in diffuse light to avoid stressing the animals, and the orientation of the gradients relative to the room was randomly reversed for some chambers to avoid systematic influence of the surroundings on copepod behavior.

The distance traveled by a female during the observation period was calculated by summing the distances from one observation to the next. This cumulative measure of distance traveled may not be accurate for two reasons. First, it captures movements in increments of $1.27 \mathrm{~cm}$; second, some females may move forward and back several times between consecutive observations. Nonetheless, this method provides a rough estimate of how active each female was within the observation chambers. The distance traveled was standardized to units of $\mathrm{cm}$ per minute, as not all females had all 30 observations due to the difficulty of observing them in the chambers under dim light. Specifically, 96/101 (95\%) behavioral assays had 27-30 observations. The other five behavioral assays (5\%), each had 10, 18, 21, 24 and 26 observations.

Statistical analyses. To test for the effects of peak extreme temperatures, DO levels and their interaction on the thermal tolerance of $T$. californicus females, we ran a generalized linear model in $\mathrm{R}$, using a binomial link function $(0=$ dead, $1=$ alive $)$. Temperature and DO were included as fixed factors. For thermal and oxygen preferences, the number of times that a female was observed in a specific position in the gradient (1-18 in the chamber) was counted to calculate the percentage of time in each position. The distribution of T. californicus in each position in the preference chambers is the main indicator of thermal and oxygen preferences. A Chi-square test was employed to test for pairwise differences in the distribution of females among treatments. For the distance traveled by females per minute, data were initially checked for normality using a Shapiro-Wilk test and the homogeneity of variance using Levene's test; both assumptions for ANOVA were not met $(P<0.05)$. Therefore, we used a non-parametric Kruskal-Wallis test to examine differences in the distance that copepods traveled per minute. $P$ values $<0.05$ are considered statistically significant. All analyses were run in $R$ (v.3.1.3).

Data deposition. Data for this study are available via the WSU Research Exchange https://doi.org/10.7273/ gjg0-p174.

Received: 18 February 2020; Accepted: 5 October 2020

Published online: 03 November 2020

\section{References}

1. Perkins, S. E., Alexander, L. V. \& Nairn, J. R. Increasing frequency, intensity and duration of observed global heatwaves and warm spells. Geophys. Res. Lett. https://doi.org/10.1029/2012gl053361 (2012).

2. Oliver, E. C. J. et al. Longer and more frequent marine heatwaves over the past century. Nat. Commun. 9, 1324. https://doi. org/10.1038/s41467-018-03732-9 (2018).

3. Frölicher, T. L., Fischer, E. M. \& Gruber, N. Marine heatwaves under global warming. Nature 560, 360-364. https://doi.org/10.1038/ s41586-018-0383-9 (2018).

4. Hobday, A. J. et al. Categorizing and naming marine heatwaves. Oceanography 31, 162-173. https://doi.org/10.5670/ocean og.2018.205 (2018).

5. Doan, X. N. et al. Extreme temperature impairs growth and productivity in a common tropical marine copepod. Sci. Rep. 9, 4550. https://doi.org/10.1038/s41598-019-40996-7 (2019).

6. Wishner, K. F. et al. Ocean deoxygenation and zooplankton: Very small oxygen differences matter. Sci. Adv. https://doi.org/10.1126/ sciadv.aau5180 (2018).

7. Roman, M. R., Brandt, S. B., Houde, E. D. \& Pierson, J. J. Interactive effects of hypoxia and temperature on coastal pelagic zooplankton and fish. Front. Mar. Sci. https://doi.org/10.3389/fmars.2019.00139 (2019).

8. Ekau, W., Auel, H., Poertner, H. O. \& Gilbert, D. Impacts of hypoxia on the structure and processes in pelagic communities (zooplankton, macro-invertebrates and fish). Biogeosciences 7, 1669-1699. https://doi.org/10.5194/bg-7-1669-2010 (2010).

9. Breitburg, D. et al. Declining oxygen in the global ocean and coastal waters. Science 359, 46. https://doi.org/10.1126/science.aam72 40 (2018).

10. Darling, E. S. \& Côté, I. M. Quantifying the evidence for ecological synergies. Ecol. Lett. 11, 1278-1286. https://doi.org/10.111 1/j.1461-0248.2008.01243.x (2008)

11. Crain, C. M., Kroeker, K. \& Halpern, B. S. Interactive and cumulative effects of multiple human stressors in marine systems. Ecol. Lett. 11, 1304-1315. https://doi.org/10.1111/j.1461-0248.2008.01253.x (2008).

12. Przeslawski, R., Byrne, M. \& Mellin, C. A review and meta-analysis of the effects of multiple abiotic stressors on marine embryos and larvae. Glob. Change Biol. 21, 2122-2140. https://doi.org/10.1111/gcb.12833 (2015).

13. Altieri, A. H. \& Gedan, K. B. Climate change and dead zones. Glob. Change Biol. 21, 1395-1406. https://doi.org/10.1111/gcb.12754 (2015).

14. Gunderson, A. R., Armstrong, E. J. \& Stillman, J. H. Annual Review of Marine Science. Annu. Rev. Mar. Sci. 8, 357 (2016).

15. Todgham, A. E. \& Stillman, J. H. Physiological responses to shifts in multiple environmental stressors: relevance in a changing world. Integr. Comp. Biol. 53, 539-544. https://doi.org/10.1093/icb/ict086 (2013).

16. Chown, S. L. \& Gaston, K. J. Macrophysiology for a changing world. Proc. R. Soc. Lond. Ser. B. 275, 1469-1478. https://doi. org/10.1098/rspb.2008.0137 (2008).

17. Tangwancharoen, S., Moy, G. W. \& Burton, R. S. Multiple modes of adaptation: regulatory and structural evolution in a small heat shock protein gene. Mol. Biol. Evol. 35, 2110-2119. https://doi.org/10.1093/molbev/msy138 (2018). 
18. Fey, S. B. et al. Opportunities for behavioral rescue under rapid environmental change. Glob. Change Biol. 25, 3110-3120. https:// doi.org/10.1111/gcb.14712 (2019).

19. Pörtner, H. O. Oxygen- and capacity-limitation of thermal tolerance: a matrix for integrating climate-related stressor effects in marine ecosystems. J. Exp. Biol. 213, 881-893. https://doi.org/10.1242/jeb.037523 (2010).

20. Portner, H. O., Bock, C. \& Mark, F. C. Oxygen- and capacity-limited thermal tolerance: bridging ecology and physiology. J. Exp. Biol. 220, 2685-2696. https://doi.org/10.1242/jeb.134585 (2017).

21. 21Verberk, W. et al. Does oxygen limit thermal tolerance in arthropods? A critical review of current evidence. Comp. Biochem. Physiol., A: Mol. Integr. Physiol. 192, 64-78, doi:https://doi.org/10.1016/j.cbpa.2015.10.020 (2016).

22. Rutledge, C. J. \& Beitinger, T. L. The effects o dissolved oxygen and aquatic surface respiration on the critical thermal maxima of three intermittent stream fishes. Environ. Biol. Fish. 24, 137-143. https://doi.org/10.1007/bf00001283 (1989).

23. Clark, T. D., Sandblom, E. \& Jutfelt, F. Aerobic scope measurements of fishes in an era of climate change: respirometry, relevance and recommendations. J. Exp. Biol. 216, 2771-2782. https://doi.org/10.1242/jeb.084251 (2013).

24. Wang, T. et al. Anaemia only causes a small reduction in the upper critical temperature of sea bass: is oxygen delivery the limiting factor for tolerance of acute warming in fishes?. J. Exp. Biol. 217, 4275-4278. https://doi.org/10.1242/jeb.104166 (2014).

25. Youngblood, J. P., Silva, C. R. B. Jr., Angilletta, M. J. \& Vander Brooks, J. M. Oxygen limitation does not drive the decreasing heat tolerance of grasshoppers during development. Physiol. Biochem. Zool. 92, 567-572. https://doi.org/10.1086/705439 (2019).

26. Jutfelt, F. et al. Oxygen- and capacity-limited thermal tolerance: blurring ecology and physiology. J. Exp. Biol. https://doi. org/10.1242/jeb.169615 (2018)

27. Lehmann, P., Javal, M. \& Terblanche, J. S. Oxygen limitation is not the cause of death during lethal heat exposure in an insect. Biol. Lett. 15, 20180701 (2019).

28. Pierson, J. J., Slater, W. C. L., Elliott, D. \& Roman, M. R. Synergistic effects of seasonal deoxygenation and temperature truncate copepod vertical migration and distribution. Mar. Ecol. Prog. Ser. 575, 57-68. https://doi.org/10.3354/meps12205 (2017).

29. Metaxas, A. \& Scheibling, R. E. Spatial heterogeneity of phytoplankton assemblages in tidepools: effects of abiotic and biotic factors. Mar. Ecol. Prog. Ser. 130, 179-199. https://doi.org/10.3354/meps130179 (1996).

30. Morris, S. \& Taylor, A. C. Diurnal and seasonal variation in physiochemical conditions within intertidal rock pools. Estuar. Coast. Shelf Sci. 17, 339-355. https://doi.org/10.1016/0272-7714(83)90026-4 (1983).

31. Crossin, G. T., Al-Ayoub, S. A., Jury, S. H., Howell, W. H. \& Watson, W. H. Behavioral thermoregulation in the American lobster Homarus americanus. J. Exp. Biol. 201, 365-374 (1998).

32. Lucic, D. et al. The effect of temperature change and oxygen reduction on zooplankton composition and vertical distribution in a semi-enclosed marine system. Mar. Biol. Res. 15, 325-342. https://doi.org/10.1080/17451000.2019.1655161 (2019).

33. Verbitsky, V. B. et al. Insights into thermal preferences of copepods in nature using the horizontal gradient method. J. Plankton Res. 39, 849-859. https://doi.org/10.1093/plankt/fbx038 (2017).

34. Byrne, M., Foo, S. A., Ross, P. M. \& Putnam, H. M. Limitations of cross- and multigenerational plasticity for marine invertebrates faced with global climate change. Glob. Change Biol. 26, 80-102. https://doi.org/10.1111/gcb.14882 (2020).

35. Enders, E. C., Wall, A. J. \& Svendsen, J. C. Hypoxia but not shy-bold phenotype mediates thermal preferences in a threatened freshwater fish, Notropis percobromus. J. Therm. Biol. 84, 479-487. https://doi.org/10.1016/j.jtherbio.2019.08.001 (2019).

36. Damgaard, R. M. \& Davenport, J. Salinity tolerance, salinity preference and temperature tolerance in the high shore harpacticoid copepod Tigriopus brevicornis. Mar. Biol. 118, 443-449. https://doi.org/10.1007/bf00350301 (1994).

37. Foley, H. B. et al. Sex-specific stress tolerance, proteolysis, and lifespan in the invertebrate Tigriopus californicus. Exp. Gerontol. 119, 146-156. https://doi.org/10.1016/j.exger.2019.02.006 (2019).

38. Harada, A. E., Healy, T. M. \& Burton, R. S. Variation in thermal tolerance and its relationship to mitochondrial function across populations of Tigriopus californicus. Front. Physiol. https://doi.org/10.3389/fphys.2019.00213 (2019).

39. Harada, A. E. \& Burton, R. S. Ecologically relevant temperature ramping rates enhance the protective heat shock response in an intertidal ectotherm. Physiol. Biochem. Zool. 92, 152-162. https://doi.org/10.1086/702339 (2019).

40. Tangwancharoen, S. \& Burton, R. S. Early life stages are not always the most sensitive: heat stress responses in the copepod Tigriopus californicus. Mar. Ecol. Prog. Ser. 517, 75-83. https://doi.org/10.3354/meps11013 (2014).

41. Schoville, S. D., Barreto, F. S., Moy, G. W., Wolff, A. \& Burton, R. S. Investigating the molecular basis of local adaptation to thermal stress: population differences in gene expression across the transcriptome of the copepod Tigriopus californicus. BMC Evol. Biol. 12, 170. https://doi.org/10.1186/1471-2148-12-170 (2012).

42. McAllen, R. \& Brennan, E. The effect of environmental variation on the reproductive development time and output of the highshore rockpool copepod Tigriopus brevicornis. J. Exp. Mar. Biol. Ecol. 368, 75-80. https://doi.org/10.1016/j.jembe.2008.10.013 (2009).

43. Graham, A. M. \& Barreto, F. S. Loss of the HIF pathway in a widely distributed intertidal crustacean, the copepod Tigriopus californicus. Proc. Natl. Acad. Sci. USA 116, 12913-12918. https://doi.org/10.1073/pnas.1819874116 (2019).

44. Goolish, E. M. \& Burton, R. S. Energetics of osmoregulation in an intertidal copepod: effects of anoxia and lipid reserves on the pattern of free amio acid accumulation. Funct. Ecol. 3, 81-89. https://doi.org/10.2307/2389678 (1989).

45. Liguori, A. L. Population level differences in life history responses to long-term $\mathrm{pH}$ stress in Tigriopus californicus. Integr. Comp. Biol. 58, E134-E134 (2018).

46. McAllen, R. \& Taylor, A. The effect of salinity change on the oxygen consumption and swimming activity of the high-shore rockpool copepod Tigriopus brevicornis. J. Exp. Mar. Biol. Ecol. 263, 227-240. https://doi.org/10.1016/s0022-0981(01)00308-2 (2001).

47. Kelly, M. W., Sanford, E. \& Grosberg, R. K. Limited potential for adaptation to climate change in a broadly distributed marine crustacean. Proc. R. Soc. B Biol. Sci. 279, 349-356. https://doi.org/10.1098/rspb.2011.0542 (2012).

48. Barreto, F. S., Schoville, S. D. \& Burton, R. S. Reverse genetics in the tide pool: knock-down of target gene expression via RNA interference in the copepod Tigriopus californicus. Mol. Ecol. Resour. 15, 868-879. https://doi.org/10.1111/1755-0998.12359 (2015).

49. Koopman, K. R., Collas, F. P. L., van der Velde, G. \& Verberk, W. Oxygen can limit heat tolerance in freshwater gastropods: differences between gill and lung breathers. Hydrobiologia 763, 301-312. https://doi.org/10.1007/s10750-015-2386-y (2016).

50. McAllen, R., Taylor, A. C. \& Davenport, J. The effects of temperature and oxygen partial pressure on the rate of oxygen consumption of the high-shore rock pool copepod Tigriopus brevicornis. Comp. Biochem. Physiol. A 123, 195-202. https://doi.org/10.1016/ s1095-6433(99)00050-1 (1999).

51. Alaykrinskaya, I. O. The functional role of hemoglobin in the hemolymph of some representatives of the family Planorbidae (Gastropoda, Pulmonata). Hydrobiol. J. 34, 84-88. https://doi.org/10.1615/HydrobJ.v34.i6.120 (1998).

52. Pavillon, J. F., Menasria, R., Forget, J., Barka, S. \& Institut, O. in Recents Progres en Chimie et Ecotoxicologie Marines Vol. 25 OceanisSerie de Documents Oceanographiques 609-650 (1999).

53. Somero, G. N. Proteins and temperature. Annu. Rev. Physiol. 57, 43-68. https://doi.org/10.1146/annurev.ph.57.030195.000355 (1995).

54. McAllen, R. \& Block, W. Aspects of the cryobiology of the intertidal harpacticoid copepod Tigriopus brevicornis (O. F. Müller). Cryobiology 35, 309-317. https://doi.org/10.1006/cryo.1997.2046 (1997).

55. Boardman, L., Sorensen, J. G., Kostal, V., Simek, P. \& Terblanche, J. S. Cold tolerance is unaffected by oxygen availability despite changes in anaerobic metabolism. Sci. Rep. 6, 32856. https://doi.org/10.1038/srep32856 (2016).

56. Stevens, M. M., Jackson, S., Bester, S. A., Terblanche, J. S. \& Chown, S. L. Oxygen limitation and thermal tolerance in two terrestrial arthropod species. J. Exp. Biol. 213, 2209-2218. https://doi.org/10.1242/jeb.040170 (2010). 
57. Finney, C. M. Salinity stress in harpacticoid copepods. Estuaries 2, 132. https://doi.org/10.2307/1351640 (1979).

58. Zeis, B., Pinkhaus, O., Bredebusch, I. \& Rüdiger, J. P. Oxygen preference of Daphnia magna is influenced by $\mathrm{P}_{\mathrm{O} 2}$ acclimation and biotic interactions. Physiol. Biochem. Zool. 78, 384-393. https://doi.org/10.1086/430039 (2005).

\section{Acknowledgments}

We thank three anonymous reviewers for constructive feedback, which helped to improve the manuscript. This research is supported by National Science Foundation IOS grant 1655822 to W.W.D.

\section{Author contributions}

K.V.D., A.Y.C. and W.W.D designed the experiment; K.S.B. and E.A.M. contributed to developing methods. K.V.D. and A.Y.C conducted the experiment and performed statistical analyses. K.V.D wrote the first draft of the manuscript. All authors contributed to the later version of the manuscript; all authors read and approved the manuscript for publication.

\section{Competing interests}

The authors declare no competing interests.

\section{Additional information}

Supplementary information is available for this paper at https://doi.org/10.1038/s41598-020-75635-z.

Correspondence and requests for materials should be addressed to K.V.D.

Reprints and permissions information is available at www.nature.com/reprints.

Publisher's note Springer Nature remains neutral with regard to jurisdictional claims in published maps and institutional affiliations.

Open Access This article is licensed under a Creative Commons Attribution 4.0 International License, which permits use, sharing, adaptation, distribution and reproduction in any medium or format, as long as you give appropriate credit to the original author(s) and the source, provide a link to the Creative Commons licence, and indicate if changes were made. The images or other third party material in this article are included in the article's Creative Commons licence, unless indicated otherwise in a credit line to the material. If material is not included in the article's Creative Commons licence and your intended use is not permitted by statutory regulation or exceeds the permitted use, you will need to obtain permission directly from the copyright holder. To view a copy of this licence, visit http://creativecommons.org/licenses/by/4.0/.

(C) The Author(s) 2020 